mendations which the other wants, and I do not doubt but thist both are infested with fallacies naturally parasitic. As the criticism which points out merits is more agreeable than the detection of vices, I will contrast them by enumerating fer of the advantages severally possessed.

The materials of the Decennium are very extensive, so that the accidental prevalence of any one lesion is improbable. They are the work of several hands, ${ }^{*}$ and therefore little liable to fallacies 'dependent on the idola spects. All cases of disense, however slight, are included (if noticed in the post mortem record); so that there is no room for the chance of arbitrary exclusion. Being a continuous series of indiscriminate autopsies, they may be supposed to represent diseased persons as a whole, not only those diseased persons who are interesting in a pathological or diagnostic point of view.

On the other hand, the Edinburgh series of post mortem examinations, being shorter, is probably richer in detail. The whole were made by one hand, and are therefore most uniform. They were made with a special view to one lesion, and by a pathologist well acquainted with it, and therefore are not likely to omit any instance.

These several advantages of one or the other series of statistics should, I think, have different weight, according to the question proposed for examination. Should the subject for investigation, for example, be the prevalence of such a lesion as cardiac disease, where the statistics differed to an extent not to be accounted for by difference of circumstances, I would trust more to the larger series. For the attention of the medical world in general, and of morbid auatomists in particular, has been of late so strongly drawn to the heart, that correct detail of its state is rarely omitted, even though the examinations are not conducted with any peculiar view of elucidating its pathology. I should be disposed to say, that the difference which exists between Dr. Gairdner's and my statistics, in this particular, was really a difference founded on nature, and not on any variation in the mode of collecting the materials. I mean that cardiac diseases are really more common at St. George's than at Edinburgh; and that both sets of statistics are valuable, as respects the proving of this point, in a direct ratio to their numerical extent. Indeed, the fact itself is $d$-priori exceedingly likely, when we know the great prevalence of diseases of a gouty and rheumatic character among the poor of London, at least on the west side. There were admitted into St. George's, during the four years ending December 31st, 1848, as many as 1014 cases thus characterised; that is, 253 per annum. The usual number of medical cases is a little under 1400 a year; so we may fairly say that 18 per cent. of the sick are thus affected. At St. Mary's, during the year 1852 , out of 460 medical cases admitted, 91 , or nearly 20 per cent., were included in the same category. The majority of these, too, are anæmic, broken-down individuals, who have seen better days, and have been subjected to the depressing influences of bad air, vicious habits, and sedentary occupations; among which class the local and organic consequences of rheumatic disease are most liable to be manifested.

Should, however, the question be the absolute prevalence of such a pathological state as emphysema of the lung, I should attach most importance to statistics collected as Dr. Gairdner's have been. The attention being particularly directed to that lesion, probably no case of it could escape observation; whereas, in ordinary autopsies, it is doubtless often passed over. Such ought to be the case no longer, now that Dr. Gairdner's valuable papers have shown the importance of the lesion; but during the ten years over which my materials extend, the facts may be fairly conjectured. But, even in such an investigation as this, a certain advantage is to be attached to an indiscriminate series of examinations, as representing more truly the population,

- Namely, Mr. Hewett, now Surgeon to St. George's Hospital ; Mr. Lee, now Assiotant-Surgeon to Kiug's Collego Hospital; Dr. Handiteld Jones, now now Assiotant-Surgeon to King's College Hospital; Dr. Handtield Jones, now
Asaistant-Physieian to st. Marg's Hospital; Mr. Pollock, now Asaistant Aseistant-Phyrieian to 8t. Mary' Hoopital; M. than selected cases, on whatever principle the seloction was made.

If, on the other hand, our intention is to inquire into the connexion of any lesion with various diseases, the advantages of the direction of special attention to the individual morbid state, and of the more careful performance of the autopsies, weigh but little. The lesion is just as likely to be noted or to be passed over in one case as another. There is no reason why emphysema, for example, should escape the eye in a case of pure dilatation of the heart, and yet be recorded in one of valvular disease-described with pneumonia, and omitted in pulmonary tubercle. Admitting that a certain percentage of examples are undetected by the less observant eye, they have an equal chance of belonging to one class as another; and, in a large number of cases, the result is nowise affected. Here again, then, I should trust most to the larger series of statistics.

I have taken advantage of the circumstance of Dr. Gairdner's criticism to weigh as a judge the several merits of two classes of statistics; viz., those where the facts, though few, are recorded with minuteness of detail, and those where the facts, though many, are observed with only ordinary care. I hope and believe I have not merged the judge in the advocate. In conclusion, I cannot forbear directing attention to the great importance, in all cases where statistics are employed, of detailing fully and freely the circumstances of their collection. If this is done, I feel sure they can never be without value; if it is not done, they are nearly always worse than worthless.

1, Hill Street, Berkeley Square, Jan. 28, 1854.

\section{CASE IN WHICH THE INHALATION OF CHLOROFORM WAS FOLLOWED BY}

\section{A FATAL RESULT.}

\section{By JOHN HARRISON, Esq., Senior Surgeon to tho Bristol Royal Infirmary.}

THE following case, in which the inhalation of chloroform was followed by death, is the first fatal case of the kind which has occurred in the Bristol Royal Infirmary, where chloroform has been used very constantly during the last six years. As death from the inhalation of chloroform is a very rare accident, I think it is the duty of every professional man to publish his experience of fatal cases, together with the post mortem appearances; since, by analysis of the facts thus recorded, useful information may be elicited for future guidance.

CAsE. Jane Morgan, aged 59, a married woman with a family, moderately stout, pale, but not otherwise of unhealthy appearance, was admitted an in-patient of the infirmary, January 19, 1854. It appeared that eight weeks previously to her admission, the patient had received an injury in the left shoulder from a severe fall. Upon examination, the humerus was found to be dislocated forwards, the head of the bone resting on the inner side of the coracoid process of the scapula. The glenoid cavity, acromion, and coracoid processes, appeared to have been uninjured. There was a slight irregularity to ve felt on the outer side of the head of the humerus, just in front, and to the inner side of the coracoid process; which led to the supposition that there had been a partial fracture at this point. The head of the humerus could be mored tolerably freely in its situation. The patient complained of very great and constant uneasiness, extending down the arm; and the examination gave her considerable pain. There was no particular heat about the shoulder; and the absence of swelling rendered the nature of the accident very obvious.

A consultation was held upon the case, which was considered to be a dislocation forwards; and it was agreed that reduction should be attempted while the patient was under the influence of chloroform. The woman, having been made acquainted with the result of the consultation, agreed to submit to the necessary measures. The stethoscopic in- 
dientions rere froumble, the beat of the heart was natural and the sir passed frooly throughout both lungs; but the chest morements on the right side. were not quite 80 froe as on the left. There was nothing that appeared in the patient's general condition to forbid the use of chloroform. In accordance with the usual practice for some years past the Bristol Infirmary, the chloroform was administered to this patient in the ward, previous to her removal into the operating theatre. The patient is transferred from the ward in a narrow wicker basket, containing a small mattress, and is easily carried by two persons. The galvanic battery is always kept at hand, in case of accidents. The chloroform of Messrs. Duncan, Flockart, and Co., of Edinburgh, is that which is employed in the infirmary, and is administered on a cupped porous sponge, care being taken to ensure a due passage of atmospheric air.

The patient, Jane Morgan, having taken no food since her breakfast, commenced the inhalation of one drachm of chlorcform, on the 21 st of January, at 2 P.s., in bed in her ward, under the superintendence of Mr. Hore, the house surgeon. Nothing unusual occurring in the patient's general condition during inhalation, a second drachm, in about five minutes from the commencement of the first, was poured uoon the sponge, and the inhalation was continued. Almost immediately after the addition of the second drachm, the chloroform was withdrawn, as the patient's breathing became stertorous; and immediately afterwards her pulse, which had hitherto continued pretty firm, was suddenly imperceptible, the respiration ceasing at the same time. The pupils were not dilated.

The tongue was at once drawn forward with a tenaculum, the face splashed with water, a window close to the patient was opened for the free admission of air, galvanism was applied, and artificial respiration commenced through the nostrils; while the trachea was being opened, and a tube introduced, through which the artificial respiration was subsequently kept up. The whole of these proceedings were executed with the greatest promptitude, and for a few minutes were followed by convulsive efforts of the respiratory muscles, which led to the hope of the patient's eventual restoration; but these again ceased. The application of galvanism and artificial respirating were, however, diligently persevered in for the space of one hour, when further efforts were considered to be unavailing.

Exaxmatior of THE BoDY, twenty-three hours after death. Rather extensive adhesions, apparently of long standing, existed between the pleura costalis and pulmonalis of the right lung. The general structure of the lungs was quite healthy, but both organs were gorged with dark fluid blood. The pericardium was natural; about an ounce of pale straw coloured fluid was found in its cavity. The external surface of the heart was natural; though, previously to opening the right ventricle, it was noticed that the anterior wall of the ventricle had collapsed, forming a cup-like concavity externally. The ventricles were examined in situ, before the great ressels were divided. The wall of the left ventricle was of a natural colour and thickness; but the wall of the right ventricle appeared at one point somewhat paler than usual. A very small quantity of quite fluid blood (not more than a drachm altogether) was found on either side of the heart. The valves were healthy ; but, near the attached surface of the mitral valve, two or three very small points of atheromatous deposit were apparent. For the length of one inch from their commencement, both the coronary arteries were much dilated, and were closely studded with atheromatous and bony deposits. Beyond this space, they assumed their usual calibre; but, at intervals, small points of atheromatous deposit were stil visible. Upon separating the heart by a transverse section through the large vessels, a quantity of perfectly fluid blood poured from them. A portion of the wall of the right ventricle was submitted to microscopic examination, as its atructure seemed rather paler, and not so well nourished as the ocher parts of the beart.

The folloring account of the appearance, under the mi- croscope, of this portion of the heart's structure, was fur. nished me by Dr. Budd :-

" $A$ considerable proportion of the fibses were found in a state of incipient fatty degenerntion. In the fasciculi thus affected, the transverse striv were vague and indistinct, or altogether effaced by minute black dots, which in parts appeared to fill the whole substance of the fibre. There were no large oil-globules. Numbers of these degenerate fasciculi had broken up into short fragments in being prepared for microscopic examination, and lay strewed in a disorderly manner about the field. Side by side with these diseased fibres lay healthy and well nourished fibres; and these last, in fact, constituted the larger proportion."

The chylopoietic viscera were quite healthy. The stomach was empty. The kidneys showed marks of old cicatrices on their convex surfaces, but were otherwise healthy. Upon being submitted to microscopic examination, they exhibited no evidences of fatty degeneration. The urine, which after death was removed from the bladder, was found to contain traces of albumen. The brain was healthy, and very pale; the vessels generally appeared emptied. There was very little fluid in the rentricles. The basilar artery showed small points of atheromatous deposit. The spinal cord was quite natural.

The parts implicated in the injury of the right shoulder were lastly subjected to examination. The head of the humerus lay in contact with the coracoid process, and to its inner side. There was a fracture, extending about an inch from above downwards, through the greater tuberosity of the humerus. Bony union had taken place, though not very firmly. The head and shaft of the bone were otherwise quite sound. The glenoid cavity, coracoid, and acromion processes were uninjured.

Perhaps there are no cases in which the advantages of chloroform are more evident than in old standing luxations of the larger joints, where reduction is to be attempted; and in this particular instance of dislocation forwards, the great pain and entire uselessness of the limb, resulting from the situation of the head of the bone, rendered it very important that the position should, if possible, be rectified. There was, as before stated, nothing in the patient's own account of herself, in her general appearance, or in her stethoscopic phenomena, to counter-indicate the use of chloroform; but I have, since the woman's death, been informed by the medical man who was called to attend her at first, when the accident to her shoulder occurred, that she was subject to occasional attacks of syncope. When the fatal symptoms supervened during the inhalation of chloroform, the appearance of the patient was that of a person suddenly attacked with syncope.

I may take this opportunity of urging the propriety of having the galvanic apparatus in readiness in all cases where chloroform is to be administered. Experience, on more than one occasion, in chloroform exigencies, has satisfied me of the high value of galvanism as a remedial agent ; and in this case, though the patient died, the respiratory movements were renewed the moment galvanism was applied. The importance of artificial respiration, in conjunction with galvanism, is of course obvious to every one.

19, Berkeley Square, Bristol, Jan. 28, 1854.

\section{CASE OF PURPURA H EMORRHAGICA TREATED BY TURPENTINE.}

\section{By GEORGE WILLIS, M.D.}

I w $\Delta$ s requested, on Nov. 10th, 1853, to visit Mr. H., a gentleman aged 22 , who had enjoyed his usual good health up to a fortnight preceding the date of my visit, when he caught a cold, which was succeeded by a troublesome hacking cough. On November 9th, whilst coughing, he brought up a large quantíty of dark coloured blood, and continued to expectorate the same whenever the cough returned, until the time of my visit.

I turned my attention first to the chest, but found no peculiarity in the respiratory sounds. 